\title{
Environmental diagnosis methodology to analyze landfill-associated risks in Colombia
}

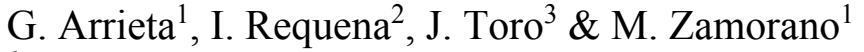 \\ ${ }^{1}$ Department of Civil Engineering, University of Granada, Spain \\ ${ }^{2}$ Department of Computer Science and Artificial Intelligence, \\ University of Granada, Spain \\ ${ }^{3}$ IDEA, Universidad Nacional de Colombia, Colombia
}

\begin{abstract}
Colombia generates 27,000 tonnes/day of waste, which is deposited into landfills. Approximately $30 \%$ of these sites do not comply with the requirements to be considered for controlled landfills. According to the legal framework, these disposal systems of solid waste are compelled to carry out an Environmental Impact Assessment (EIA) process in order to minimize their associated problems. Even though there are tools designed to perform the EIA prior to the landfill construction, this is not the case for the follow-up and control stages of the operation phase. The University of Granada (Spain) developed a diagnosis methodology called EVIAVE, which allows for quantifying - through indexes the environmental impact of landfills according to location and exploitation conditions, which allows for the implementation of environmental management plans. EVIAVE was designed for municipal landfills according to the European Union's legal framework. However, it has been successfully applied in Chile, Venezuela and Iran with adaptations regarding their legal, socio-economic and ecosystem features. This work shows EVIAVE's adaptation in Colombia, in order to diagnose active landfills. Modifications include flora and fauna, which allow for obtaining a wider description of the environment and updating the methodology according to the Convention on Biological Diversity. The assessment of environmental descriptors was also reformulated to cover the concept of vulnerability. This enables having more accuracy when assessing the predisposition of environmental elements to potential impacts generated by landfills' operations. EVIAVE's application in 16 Colombian landfills allowed for identifying the affected elements due to operation and maintenance
\end{abstract}


conditions. This facilitates decision-making processes regarding the environmental management plans. It can be concluded that this methodology is a feasible and effective tool to diagnose the state of the environment in a landfill's influence area, and to analyze landfill-associated risks in Colombia, because it takes into account environmental threats and vulnerabilities, as well as the follow-up and the control stages in EIA processes.

Keywords: EVIAVE methodology, Environmental Impact Assessment, follow-up, waste management.

\section{Introduction}

By the end of the twentieth century there was a dramatic increase in the production of Municipal Solid Waste (MSW) [12]. As a result, cities around the world currently generate around 1.3 billion tonnes of solid waste per year, an amount that is expected to rise to 2.2 billion tonnes by 2025 [10]. Due to the risks associated with solid waste, its management has gained relevance in modern society [13]. Solid Waste Management (SWM) has been implemented as a prevention and mitigation strategy, which has presented different efficiency rates. Therefore, landfills are still a source of negative environmental impacts [7, $16,24]$.

In Colombia, the generation of MSW has been increasing since the fifties. By 2013 , the waste production per capita was $0.57 \mathrm{Kg} /$ day, with an average of 27,000 tonnes/day $[18,19]$, and $97.2 \%$ of this waste was disposed in landfills [18]. Although the landfill construction stage is officially regulated by the Environmental Impact Assessment (EIA) process in this country, the follow-up and control in the operation phase are deficient, due to the lack of tools and methods to carry out these activities [20].

The University of Granada (in Spain) has developed a methodology called EVIAVE to diagnose landfills, and it has been successfully applied in Spain, Chile, Venezuela and Iran $[1,6,25]$ with a previous adaptation according to the ecosystem, legal and socioeconomic features of each country [24]. This methodology may also be used to perform the follow-up and control of MSW landfills in Colombia.

This work proposes a modification to EVIAVE so that it can be used as a follow-up and control tool for the operation of MSW landfills, according to the Colombian legal and ecosystem context. Therefore, the following section describes EVIAVE methodology; section 3 presents the adaptation proposal corresponding to the Colombian context; and section 4 exposes its application in national landfills. Finally, section 5 includes the main conclusions and recommendations that emerge from this work.

\section{Landfill environmental diagnosis methodology - EVIAVE}

EVIAVE was developed in 2005 by the Superior Technical School of Roads, Canals and Harbours (University of Granada, Spain). This methodology has been a research object, with results published in scientific specialized journals $[1,6$, 
24, 25]. EVIAVE's main foundation is the cause-effect analysis of the interactions between landfill and environment, by using environmental indexes that allow for quantitatively assessing the environmental status of a project's influence area, particularly in its operation phase. Given these characteristics, it has a low uncertainty level and is appropriate to be applied in the follow-up and control stages. Moreover, EVIAVE can be adapted to the current environmental regulations of the European Union, South America and Asia. The assessment of the environment-landfill interaction is developed through a set of indexes according to four levels, whose values and classification are summarized next (a full description of EVIAVE methodology is available at: http://arai.ugr.es leiadifusa/) $[1,6,24,25]$.

\section{Level 1}

This level includes 9 environmental descriptors valued from 1 to 5; and 26 landfill variables, 14 of them related to exploitation operations and 12 related to the location features of the discharge point (Table 1).

Table 1: $\quad$ Indexes used in EVIAVE - level 1.

\begin{tabular}{|c|c|c|}
\hline Environmental descriptors & \multicolumn{2}{|c|}{ Landfill variables } \\
\hline 1. Water use $\left(\mathrm{A}_{1}\right)$ & 1. Settling of waste & 14. Waste types \\
\hline 2. Type of surface water mass $\left(\mathrm{A}_{2}\right)$ & 2. Final cover & 15. Aquifer characteristics \\
\hline 3. Surface water quality $\left(\mathrm{A}_{3}\right)$ & 3. Compaction & $\begin{array}{c}\text { 16. Distance from } \\
\text { infrastructure }\end{array}$ \\
\hline 4. Water use $\left(\mathrm{B}_{1}\right)$ & 4. Control of gas & $\begin{array}{c}\text { 17. Distance from surface } \\
\text { water mass }\end{array}$ \\
\hline 5. Ground water quality $\left(\mathrm{B}_{2}\right)$. & 5. Control leachate & 18. Distance from population \\
\hline 6. Air quality $\left.\mathrm{C}_{1}\right)$ & 6. Landfill age & 19. Erosion \\
\hline 7. Soil use 7. $\left(\mathrm{D}_{1}\right)$ & 7. State of roads & 20. Fault \\
\hline 8 Vegetation type $\left(\mathrm{D}_{2}\right)$ & 8. Waterproofing & $\begin{array}{c}\text { 21. Discharge point } \\
\text { localization in flood-water }\end{array}$ \\
\hline 9. Vegetal cover $\left(\mathrm{D}_{3}\right)$ & 9. Covering material & 22. Pluviometry \\
\hline & 10. Safety & 23. Point located in flood zone \\
\hline & 11. Surface drainage & $\begin{array}{c}\text { 24. Point located in area of } \\
\text { surface runoff }\end{array}$ \\
\hline & 12. Slopes of waste & 25. Seismic risk \\
\hline & 13. Population size & 26. Wind \\
\hline
\end{tabular}

The assessment of the landfill variables is made through the Contamination Risk Index (CRI) (Eq. (1)), where $\mathrm{C}_{\mathrm{j}}$ corresponds to the landfill variable and $\mathrm{W}_{\mathrm{j}}$ is the weighting of variable $\mathrm{j}$.

$$
\mathbf{C R} \mathbf{I}_{\mathbf{j}}=C_{j} x W_{j}
$$




\section{Level 2}

The Probability of Contamination $\left(\mathrm{Pbc}_{\mathrm{i}}\right)$ is calculated at this level. This index must consider the scale of operation, waste characteristics and the spread of waste disposals in the landfill environment because suitable siting, design and landfill operation are essential in order to eliminate or minimize associated adverse environmental impacts. It is thus possible to analyze two indexes: Probability of Contamination due to landfill operation, and Probability of Contamination because of landfill siting. Probability of contamination is expressed by Eq. (2), where $n$ is the number of variables affecting each environmental element; $\mathrm{CRI}_{\mathrm{j}}$ is the Contamination Risk Index for each variable

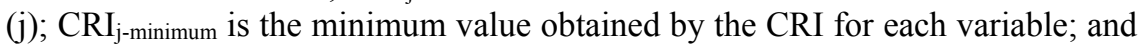
$\mathrm{CRI}_{\mathrm{j} \text {-maximum }}$ is the maximum value obtained by the CRI for each variable. It may have values between 0 and 1 .

$$
\mathrm{Pb}_{\mathrm{ci}}=\frac{\sum_{\mathrm{j}=1}^{\mathrm{j}=\mathrm{n}} \mathrm{CRIj}-\sum_{\mathrm{j}=1}^{\mathrm{j}=\mathrm{n}} \mathrm{CRIj}{ }_{\min }}{\sum_{\mathrm{j}=1}^{\mathrm{j}=\mathrm{n}} \mathrm{CRIj}{ }_{\text {max }}-\sum_{\mathrm{j}=1}^{\mathrm{j}=\mathrm{n}} \mathrm{CRIj}{ }_{\min }}
$$

The environmental value $\left(\mathrm{eV}_{\mathrm{i}}\right)$ is also determined at level 2 for each one of the environmental elements: i) surface water, ii) ground water, iii) atmosphere, iv) soil; and v) human health. This value is calculated through Equations (3)-(6). The eV, also specified at this level, identifies and quantifies the environmental assessment of each environmental element at the landfill site. This index takes into account the relationship between the environmental, social and political characteristics of the site, the emissions at the discharge point, and the environmental importance of each element in the immediate context of the landfill. It also provides information concerning the suitability of the landfill location. EVIAVE does not include a mathematical expression for human health; it always receives the maximum value (5).

$$
\begin{gathered}
\mathrm{eV}_{\text {surface-water }}=\frac{\mathrm{A}_{1}+\mathrm{A}_{2}+\mathrm{A}_{3}}{3} \\
\mathrm{eV}_{\text {ground-water }}=\frac{\mathrm{B}_{1}+\mathrm{B}_{2}}{2} \\
\mathrm{eV}_{\text {atmosphere }}=\mathrm{C}_{1} \\
\mathrm{eV}_{\text {soil }}=\frac{\mathrm{D}_{1}+\mathrm{D}_{2}+\mathrm{D}_{3}}{3}
\end{gathered}
$$

\section{Level 3}

The Environmental Risk Index $\mathrm{ERI}_{\mathrm{i}}$ is defined at the third level. It determines the potential risks for each one of the environmental elements and reflects the interaction between the discharge point and the environment (see Eq. (7), where ERI is the Environmental Risk Index for each one of the environmental elements 
(i); $\mathrm{Pbc}_{\mathrm{i}}$ is their Probability of Contamination; and $\mathrm{eV}_{\mathrm{i}}$ corresponds to their environmental value).

$$
\mathbf{E R I} \mathbf{I}_{\mathbf{i}}=P b c_{i} x e V_{i}
$$

\section{Level 4}

The Environmental Landfill Index or Impact Index (ELI) is determined at the fourth -and last- level. This index represents the total impact generated by the landfill. This information is useful for the follow-up in the EIA process because it allows evaluating the management plans efficiency through an accurate identification of the main focal points producing impacts; and it also takes into account the interaction between the project's activities and the environmental elements (see Eq. (8)), where ELI is Environmental Landfill Index and $\mathrm{ERI}_{\mathrm{i}}$ corresponds to the Environmental Risk Index for each one of the environmental elements [1, 6, 24, 25].

$$
\mathbf{E L I}=\sum E R I_{i}
$$

\section{Modification of EVIAVE methodology and application in Colombia}

Despite the scope of EVIAVE, a series of modifications are necessary to obtain an adequate adaptation so that this methodology can be used as a tool in the Colombian EIA process, and particularly, in the follow-up and control activities in landfills.

\subsection{Weaknesses of EVIAVE methodology regarding its application in Colombia}

The analysis of EVIAVE within the Colombian context allowed identifying two main weaknesses: i) the absence of flora and fauna as environmental elements that may be affected by the landfill; and ii) the procedure to assign values to the environmental elements. These two aspects are justified below.

- Flora and fauna diversity. Biodiversity is the variety of life in the world at every level, from genes to global populations that share from a small habitat to large global ecosystems [3]. Colombia is one of the leading nations with respect to flora and fauna biodiversity, so it must be considered as a country with high environmental priority [3]. There is enough scientific evidence pointing out the negative impacts of landfills on the diversity of individuals and populations [8]. Therefore, the proposal of this work is the inclusion of two new environmental elements (flora and fauna) that enable the inclusion of biodiversity in the landfill evaluation process.

- Environmental vulnerability. The environmental risk is a widely studied condition by several fields of knowledge [14] and it may be defined as the probability that an event will occur and its negative consequences. The generic factors constituting risk analysis are threat and vulnerability (Eq. (9)).

$$
\text { Risk }=\text { Threat } x \text { Vulnerability }
$$


The threat is represented by a phenomenon, a substance, and activity or a condition that may produce environmental impacts. In the studied case, the threat would correspond to the landfill's operation activities and the features of solid waste.

The vulnerability, on the other hand, is defined as the susceptibility of systems, persons or places (due to their inherent or acquired characteristics) to impacts, tensions or disturbances, and their ability to adapt to changing conditions $[2,21]$. The vulnerability is a relevant factor in environmental evaluations because it helps increasing the objectivity in decision-making processes and it also provides environmental profiles that allow identifying priorities and areas where an urgent intervention is needed [17].

EVIAVE is developed in a risk context; therefore, the risk is incorporated through the ERI index (Eq. (7)). Since vulnerability is a main component in risk analysis, this work proposes its inclusion according to the principles and criteria for the eVi assignment (Eqs (3)-(6)).

\subsection{EVIAVE modification proposal}

Taking into account the aforementioned arguments, the following modifications are proposed: i) broadening the environmental elements and defining their environmental descriptors; and ii) changing the assessment of environmental descriptors according to a perspective that includes the concept of vulnerability.

- Broadening the environmental elements and defining their environmental descriptors. The flora and fauna located in a landfill's influence area may be affected by its activities. This work proposes their inclusion as environmental elements, and the assignation of environmental descriptors. For fauna: i) threatened fauna species $\left(\mathrm{F}_{1}\right)$; and ii) fauna habitat quality $\left(\mathrm{F}_{2}\right)$. For flora: i) threatened flora species $\left(\mathrm{G}_{1}\right)$.

The indicator "number of threatened species" is adopted for the definition of these environmental descriptors, according to the Red List Index proposed by the International Union for Conservation of Nature - IUCN [5, 11]. The features, conditions and values were defined according to the work by Toro et al. [21, 22] which includes the concept of vulnerability. Table 2 presents the proposed environmental descriptors regarding threatened species and their values.

EVIAVE methodology also determines an environmental value $\left(\mathrm{eV}_{\mathrm{i}}\right)$ for each environmental descriptor. Equations (10) and (11) show how those values are assigned for the case of fauna and flora.

$$
\begin{gathered}
\mathrm{eV}_{\text {wild life }}=\frac{\mathrm{F}_{1}+\mathrm{F}_{2}}{2} \\
\mathrm{eV}_{\mathrm{Fl}}=G_{l}
\end{gathered}
$$

In order to define the features, conditions and values for the environmental descriptors regarding Fauna habitat quality $\left(\mathrm{F}_{2}\right)$, the Remnant Vegetation Index (RVI) proposed by Márquez [15] was adopted. This index is a modification of the Habitat Index used by Hannah et al. [9], which expresses an area's natural 
vegetation cover as a percentage of its total. See Eq. (12), where RVI is Remnant Vegetation Index; RVA is Remnant Vegetation Area, and $T_{a}$ corresponds to the total area of the unit (in square kilometers). Five transformation categories are considered in the value assignment. Table 3 shows the proposed environmental descriptors for fauna habitat quality and their values, which according to EVIAVE methodology oscillate between 1 and 5.

$$
\mathbf{R V I}=\left(R V A / T_{a}\right) x 100
$$

Table 2: Features and quantification determining the environmental descriptors of flora and fauna - threatened species [22].

\begin{tabular}{|c|c|c|}
\hline \multirow{2}{*}{ Features } & \multicolumn{2}{|c|}{ Quantification } \\
\cline { 2 - 3 } & Condition & Value \\
\hline \multirow{2}{*}{$\begin{array}{c}\text { Fauna threatened } \\
\text { species }\left(\mathrm{F}_{1}\right)\end{array}$} & Threatened species - low & 1 \\
\cline { 2 - 3 } & Threatened species - medium-low & 2 \\
\cline { 2 - 3 } $\begin{array}{c}\text { Flora threatened } \\
\text { species }\left(\mathrm{G}_{1}\right)\end{array}$ & Threatened species - medium & 3 \\
\cline { 2 - 3 } & Threatened species - high & 4 \\
\cline { 2 - 3 } & Threatened species - very high & 5 \\
\hline
\end{tabular}

Table 3: Features and quantification determining the environmental descriptors of fauna - habitat quality $[15,22]$.

\begin{tabular}{|c|c|c|}
\hline \multirow{2}{*}{ Features } & \multicolumn{2}{|c|}{ Quantification } \\
\cline { 2 - 3 } & Condition & Value \\
\hline \multirow{3}{*}{$\begin{array}{c}\text { Fauna } \\
\text { habitat } \\
\text { quality } \\
\left(\mathrm{F}_{2}\right)\end{array}$} & Habitat with a low transformation: $\mathrm{RVI}>70$ & 1 \\
\cline { 2 - 3 } & Habitat with a medium-low transformation: $50 \% \leq \mathrm{RVI}<70$ & 2 \\
\cline { 2 - 3 } & Habitat with a medium transformation: $20 \% \leq \mathrm{RVI}<50$ & 3 \\
\cline { 2 - 3 } & Strongly transformed habitat: RVI $<10 \%$ & 4 \\
\hline
\end{tabular}

- Changing the assessment of environmental descriptors according to a perspective that includes the concept of vulnerability. Originally, EVIAVE assigns values from 1 to 5 (from lowest to highest) to some environmental descriptors $[24,25]$ according to the concept of vulnerability; but for the rest of them, the values are calculated based on their state or quality, with criteria that do not include the vulnerability perspective. In this sense, it is necessary to unify the assessment criteria and adapt them to the vulnerability and risk concepts. Toro et al. [22] developed a methodological proposal that includes EVIAVE's 
environmental descriptors, where the maximum values are assigned to the descriptors presenting a higher susceptibility to disturbances and the lowest values were given to those showing a lower predisposition to change. As a result, there is an inverse correlation between the condition of the environmental element and its vulnerability. This proposal by Toro et al. [22] is included in the studied case, and therefore the values of the environmental descriptors $A_{3}, B_{2}$, $\mathrm{C} 1 \mathrm{y} \mathrm{D}_{3}$ are modified (see Table 4). The maximum value (5) is assumed in the case of the environmental element "human health" for every landfill included in the environmental diagnosis, because this is a constant element in every waste disposal location $[24,25]$.

Table 4: Modification proposal of the values assigned to environmental descriptors.

\begin{tabular}{|c|c|c|c|c|}
\hline \multirow{2}{*}{$\begin{array}{c}\text { Environmental } \\
\text { element }\end{array}$} & \multirow{2}{*}{$\begin{array}{c}\text { Environmental } \\
\text { descriptor }\end{array}$} & \multirow{2}{*}{ Condition } & \multicolumn{2}{|c|}{ Value } \\
\hline & & & Or & Mo \\
\hline \multirow{5}{*}{ Surface Water } & \multirow{5}{*}{$\begin{array}{l}\text { Surface water } \\
\text { quality }\left(\mathrm{A}_{3}\right)\end{array}$} & Water in a very good condition & 5 & 1 \\
\hline & & Water in a very good condition & 4 & 2 \\
\hline & & Water in a good condition & 3 & 3 \\
\hline & & Water in an acceptable condition & 2 & 4 \\
\hline & & Poor quality water & 1 & 5 \\
\hline \multirow{5}{*}{ Ground water } & \multirow{5}{*}{$\begin{array}{l}\text { Ground water } \\
\text { quality }\left(\mathrm{B}_{2}\right)\end{array}$} & Water in a very good condition & 5 & 1 \\
\hline & & Water in a good condition & 4 & 2 \\
\hline & & Water in an acceptable condition & 3 & 3 \\
\hline & & \begin{tabular}{|l|} 
Poor quality water \\
\end{tabular} & 2 & 4 \\
\hline & & Water with a very poor quality & 1 & 5 \\
\hline \multirow{5}{*}{ Atmosphere } & \multirow{5}{*}{ Air quality $\left(\mathrm{C}_{1}\right)$} & Very good air quality & 5 & 1 \\
\hline & & Good air quality & 4 & 2 \\
\hline & & Fair air quality & 3 & 3 \\
\hline & & Bad air quality & 2 & 4 \\
\hline & & Very bad air quality & 1 & 5 \\
\hline \multirow{5}{*}{ Soil } & \multirow{5}{*}{$\begin{array}{l}\text { Vegetal cover } \\
\qquad\left(\mathrm{D}_{3}\right)\end{array}$} & $>75 \%$ & 5 & 1 \\
\hline & & $51-75 \%$ & 4 & 2 \\
\hline & & $26-50 \%$ & 3 & 3 \\
\hline & & $6-25 \%$ & 2 & 4 \\
\hline & & $<5 \%$ & 1 & 5 \\
\hline
\end{tabular}

\section{Application}

In order to assess the proposed modifications, a comparison was made between the original EVIAVE and its modified version, particularly in two of the largest landfills in Colombia, which are located in natural regions presenting different 
environmental conditions: 1. Doña Juana landfill (DJ), located in Bogota; and 2. Navarro landfill, located in Cali.

\subsection{Results analysis}

Table 5 presents in detail the comparison between the qualification obtained by the original indexes (Or) and the modified indexes (Mo) of EVIAVE methodology, for each one of the studied landfills. These results are further analyzed in the following subsections.

Table 5: Indexes of original and modified EVIAVE.

\begin{tabular}{|c|c|c|c|c|c|c|c|}
\hline \multirow{3}{*}{$\begin{array}{l}\text { EVIAVE } \\
\text { methodology } \\
\text { indexes }\end{array}$} & \multirow{3}{*}{$\begin{array}{l}\text { Environmental } \\
\text { elements }\end{array}$} & \multicolumn{6}{|c|}{ Studied landfills } \\
\hline & & \multicolumn{3}{|c|}{ Doña Juana } & \multicolumn{3}{|c|}{ Navarro } \\
\hline & & $\mathrm{O}$ & $\mathrm{M}$ & $\% * *$ & $\mathrm{O}$ & $\mathrm{M}$ & $\% * *$ \\
\hline \multirow[t]{7}{*}{$\mathrm{eV}_{\mathrm{i}}$} & Sw & 3.7 & 5.0 & +35.1 & 3.7 & 4.7 & +27.0 \\
\hline & Gw & 2.0 & 4.0 & +100 & 3.0 & 4.0 & +33.3 \\
\hline & At & 1.0 & 5.0 & +400 & 2.0 & 3.0 & +50.0 \\
\hline & So & 3.0 & 3.7 & +23.3 & 3.3 & 2.7 & -18.2 \\
\hline & $\mathrm{Hh}$ & 5.0 & 5.0 & 0.0 & 5.0 & 5.0 & 0.0 \\
\hline & W1 & - & 4.5 & - & - & 4.0 & - \\
\hline & $\mathrm{Fl}$ & - & 5.0 & - & - & 3.0 & - \\
\hline \multirow[t]{7}{*}{$\mathrm{ERI}_{\mathrm{i}}$} & Sw & 1.7 & 2.3 & +35.3 & 3.1 & 4.0 & +29 \\
\hline & $\mathrm{Gw}$ & 1.0 & 2.11 & +111 & 2.6 & 3.4 & +30.8 \\
\hline & At & 0.6 & 2.9 & +383 & 1.8 & 2.7 & +50 \\
\hline & So & 1.5 & 1.9 & +26.7 & 2.6 & 2.1 & -19.2 \\
\hline & $\mathrm{Hh}$ & 3.1 & 3.1 & 0.0 & 4.5 & 4.5 & 0.0 \\
\hline & $\mathrm{Wl}$ & - & 2.2 & - & - & 3.5 & - \\
\hline & $\mathrm{Fl}$ & - & 2.6 & - & - & 2.6 & - \\
\hline \multicolumn{2}{|c|}{ ELI } & 8.09 & 12.4 & +53.3 & 14.8 & 16.5 & +11.5 \\
\hline \multicolumn{2}{|c|}{ ELI classification } & Low & Med & - & Med & High & - \\
\hline
\end{tabular}

O: Original; M: Modified; *Surface water (Sw); Ground water (Gw); Atmosphere (At), Soil (So); Human health (Hh); Wild Life (Wl); Flora (Fl). ** \% Change Or vs Mo.

\subsubsection{Probability of Contamination $\left(\mathrm{Pbc}_{\mathrm{i}}\right)$}

The determination of this index for each one of the environmental elements depends on the classification of the variables $\left(\mathrm{C}_{\mathrm{j}}\right)$, which have not been modified. Therefore, this index has the same values for both cases (original and modified EVIAVE). The obtained values concur with the features in the landfills' locations, as well as with the operation and control activities.

\subsubsection{Environmental value $\left(\mathrm{eV}_{\mathrm{i}}\right)$}

The proposed modifications affect the $\mathbf{e V}_{\mathbf{i}}$ calculation for the different environmental elements. The values show important changes when comparing 
the results obtained after the application of original and modified EVIAVE (see Table 5). In this sense, it can be observed that the modifications made to the value assignment for environmental descriptors, which include the vulnerability perspective, are successful in capturing the environmental susceptibility of an influence area to the potential impacts generated by the landfill.

The analysis of the eVi index is important because it helps identifying the most vulnerable environmental elements, and this information may facilitate the follow-up and control processes because it allows assessing the management measures for those environmental elements that present higher risks.

\subsubsection{Environmental Risk Index (ERI}

EVIAVE modified methodology shows an increase in the values obtained for the ERI index (see Table 5 and Figure 1). These results are related to the growth of the eVi values that successfully capture the environmental risk. Even when the $\mathrm{Pbc}_{\mathrm{i}}$ indexes are constant in the original and modified ERI, this latter is higher for those cases in which vulnerability increases, and this concurs with the risk analysis that assesses the interactions between threats and vulnerability (Eq. (9)). These characteristics of the ERI index are very useful when planning and implementing management plans, as well as follow-up and control activities, because in some cases the vulnerability of the environmental elements is a factor that cannot be changed, so this tool allows identifying the main features of the landfill's operation that need to be adjusted to diminish threats, and thus, lessen risks.

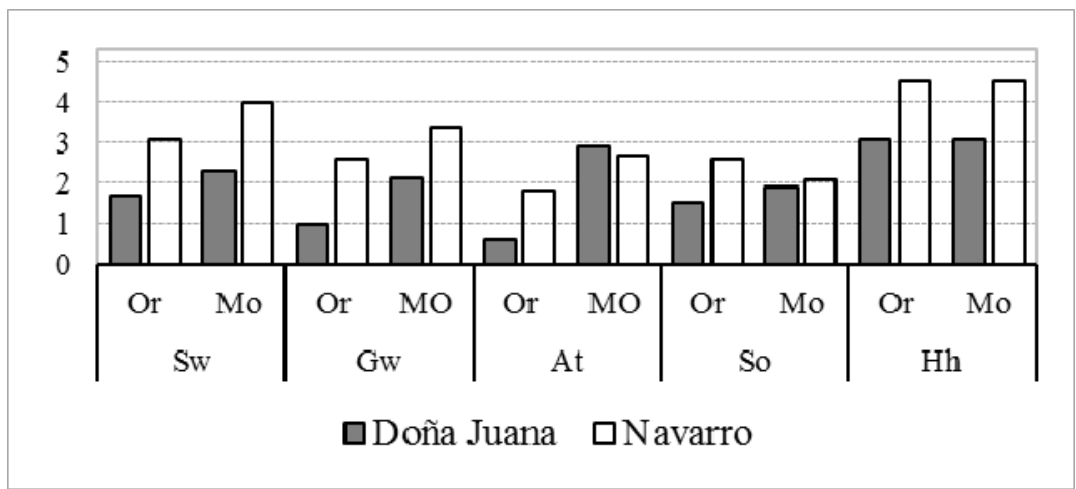

Figure 1: Comparative values of the $\mathrm{ERI}_{\mathrm{i}}$ index for original (Or) and modified (Mo) EVIAVE.

\subsubsection{Environmental Landfill Index or Impact Index (ELI)}

The results of the ELI index were higher for the modified methodology in comparison to the original, but the trend among the studied landfills was maintained: Navarro obtanied the higher rate for both cases (original and modified EVIAVE), and Doña Juana got the lowest (see Table 5, Figure 2). 
The ELI index is significant for the EVIAVE methodology because it allows to carry out a global analysis of the environmental affection generated by the interaction between landfill and environment. The changes regarding the obtained values for the environmental descriptors when a vulnerability perspective is included allow capturing the environment's resilience or response capacity with respect to the landfill's exploitation activities and the general MSW features. This enables a more adequate follow-up and control because the environmental aspects of the most pontentially polluting activity can be identified, as well as the environmental elements that demand a prioritized and detailed monitoring.

It can be also observed that the ELI value directly corresponds to the landfill's exploitation level and its location suitability. Thus, the landfill with the highest ELI (El Navarro) is located in a zone with high environmental vulnerability and it also presents important thechnical failures in its exploitation. As a result, this landfill has generated significant environmental impacts on surface and ground water, as well as on the health of the community who uses this resource as drinkable water and for agricultural activities.

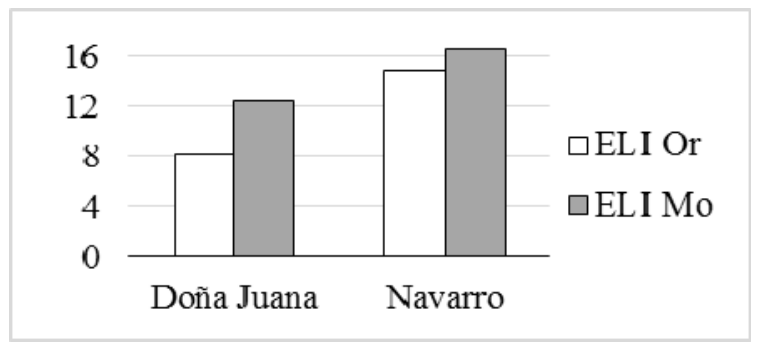

Figure 2: Comparative values of the ELI index for original (Or) and modified (Mo) EVIAVE.

\section{Conclusions}

This work presents a modification to EVIAVE methodology with the objective of adapting it to the social, political and environmental features in Colombia. In order to do so, two new environmental elements (flora and fauna) have been included, thus taking into consideration the recommendations made by the Convention on Biological Diversity. Moreover, this study also proposes the incorporation of the vulnerability concept when it comes to analyzing the environmental value of the environmental elements included in the methodology.

The application of this modified EVIAVE has revealed that the proposed changes allow obtaining values of environmental indexes that present a more precise correspondence to the landfill's environmental location features. The accuracy of this adjusted methodology reflects the risk analysis in a more realistic fashion because it takes into account threats, vulnerabilities and the follow-up and control processes of EIA. In other words, it allows identifying 
those environmental elements that present the highest damages and the activities that generate bigger impacts. This facilitates the decision-making process in the activities included in environmental management plans.

The use of this modified methodology has revealed that it is a feasible and effective tool to diagnose the status of the environment in a landfill's influence area, in relation to its location and exploitation.

\section{References}

[1] Abedinzadeh N, Abedinzadeh F, Abedi T. Environmental Diagnosis by Eviave Methodology to Planning and Decision-Making for Municipal Waste Landfills in Iran. World Appl Sci J 2013; 21: 1640-50.

[2] Adger WN. Vulnerability. Glob Environ Chang 2006; 16: 268-81.

[3] Alexander Von Humboldt Institute (AvHI). Biodiversity 2014. Status and trends of continental biodiversity in Colombia. Colombia: AvHI; 2014.

[4] Butt T, Lockley E, Oduyemi K. Risk assessment of landfill disposal sites - State of the art. Waste Management Volume 28, Issue 6, 2008: 952-964.

[5] Butchart, S, Akcakaya R, Kennedy E, Hilton-Taylor C. Biodiversity indicators based on trends in conservation status: strengths of the IUCN Red List Index. Conserv Biol 2006; 20: 579-581.

[6] Calvo F, Moreno B, Zamorano M, Szanto M. Environmental diagnosis methodology for municipal waste landfills. Waste Manag 2005; 25: 76879.

[7] De Oliveira S, Borenstein D. A decision support system for the operational planning of solid waste collection. Waste Manage 2007; 27: 1286-97.

[8] El-Fadel M, Findikakis A, Leckie J. Environmental impacts of solid waste landfilling. J Environ Manag 1997; 50: 1-25.

[9] Hannah L, Carr L, Lankerani A. Human disturbance and natural habitat: a biome level analysis of a global data set. Biodivers Conserv 1995; 4: 128155.

[10] Hoornweg D, Bhada-Tata P. What a Waste: A Global Review of Solid Waste Management. World Bank, Washington, DC; 2012. Available at: https://openknowledge.worldbank.org/handle/10986/17388

[11] IUCN. Guidelines for application of IUCN Red List criteria at regional levels: version 3.0. International Union for the Conservation of Nature. IUCN Species Survival Commission, IUCN, Gland and Cambridge; 2003.

[12] Leão S, Bishop I, Evans D. Spatial-temporal model for demand and allocation of waste landfills in growing urban regions. Comput Environ Urban Syst 2004; 28: 353-85.

[13] Ljunggren $M$. Including indirect environmental impacts in waste management planning. Resour Conserv Recycling 2003; 38: 213-41.

[14] Martorell S, Villamizar M, Martón I, Villanueva J, Carlos S, Sánchez A. Evaluation of risk impact of changes to surveillance requirements addressing model and parameter uncertainties. Reliab Eng Syst Saf 2014; 126: $153-165$. 
[15] Márquez G. Transformation of ecosystems and living conditions in Colombia. PhD dissertation to obtain the title of Doctor in Tropical Ecology. Universidad de los Andes, Venezuela, 2005. Available at: http://www.saber.ula.ve

[16] Radenkova-Yaneva M, Kostakeva E, Toshev D. Contaminant migration from sanitary landfill leachate through soil monoliths. Water Sc Technol 1995; 32: 215-19.

[17] SOPAC-UNEP. Building Resilience in SIDS. The environmental vulnerability index. United Nations Environmental Programme (UNEP), South Pacific Applied Geoscience Commission (SOPAC). USA; 2005

[18] Superintendencia de Servicios Públicos Domiciliarios [Superintendent of Public Services] (SSPD). Estudio sectorial de aseo-2013 [Status of solid waste disposal in Colombia-Diagnosis-2013]. Colombia: SSPD; 2013. Available at $\mathrm{http}: / /$ publicaciones.superservicios.gov.co/index

[19] Superintendencia de Servicios Públicos Domiciliarios [Superintendent of Public Services] (SSPD). Situación de la disposición final de residuos sólidos en Colombia - Diagnóstico [Status of solid waste disposal in Colombia-Diagnosis]. Colombia: SSPD; 2011. Available at http://publicaciones.superservicios.gov.co

[20] Toro J, Requena I, Zamorano M. Environmental impact assessment in Colombia: critical analysis and proposals for improvement. Environ Impact Asses Rev 2010; 30: 247-61.

[21] Toro J, Requena I, Zamorano M. Determining Vulnerability Importance in Environmental Impact Assessment. The case of Colombia. Environ Impact Asses Rev 2012; 32: 107-17.

[22] Toro, J, Requena I, Duarte O. A qualitative method proposal to improve environmental impact assessment. Environ Impact Asses Rev 2013; 43: 920.

[23] Vitousek P, Mooney H, Lubchenco J, Melillo J. Human Domination of Earth's Ecosystems. Science 1997; 277: 494-499.

[24] Zamorano M, Paolini A, Ramos A, Rodríguez M. Adapting EVIAVE methodology as a planning and decision-making tool in Venezuela. $\mathrm{J}$ Hazard Mater 2009; 172: 993-1006.

[25] Zamorano M, Garrido E, Moreno B, Paolini A, Ramos A. Description of the methodology EVIAVE for the environmental diagnosis of municipal waste landfills. J Sustain Dev and Plan 2006;1: 1-14 